\title{
Clinical efficacy and safety of the Jinfeng pill in the adjuvant treatment of infertility in patients with polycystic ovary syndrome: a systematic review and meta-analysis of randomized controlled trial
}

\author{
Yu Xü ${ }^{1 \#}$, Yan-Mei Han ${ }^{2 \#}$, Wen $\mathrm{Xu}^{1}$, Chun $\mathrm{Shi}^{3}$, Yan-E Chen ${ }^{4}, \mathrm{Na} \mathrm{Li}^{5}$ \\ ${ }^{1}$ Department of Reproductive Medicine, Hainan Modern Women and Children's Hospital, Haikou, China; ${ }^{2}$ Department of Medical Genetics, \\ Haikou Hospital of Maternal and Child Health, Haikou, China; ${ }^{3}$ Department of Obstetrics, Haikou Hospital of Maternal and Child Health, Haikou, \\ China; ${ }^{4}$ Department of Gynecology, Haikou Hospital of Maternal and Child Health, Haikou, China; ${ }^{5}$ Department of Surgical Anesthesia, Hainan \\ Women and Children's Medical Center, Haikou, China \\ Contributions: (I) Conception and design: Y Xu; (II) Administrative support: N Li; (III) Provision of study materials or patients: YM Han; (IV) \\ Collection and assembly of data: C Shi; (V) Data analysis and interpretation: YE Chen; (VI) Manuscript writing: All authors; (VII) Final approval of \\ manuscript: All authors. \\ "These authors contributed equally to this work and should be considered as co-first authors. \\ Correspondence to: Na Li. Department of Surgical Anesthesia, Hainan Women and Children's Medical Center, Haikou 570206, China. \\ Email: lina133799@163.com.
}

\begin{abstract}
Background Polycystic ovary syndrome (PCOS) is a common endocrine disease leading to infertility in women of childbearing age. Adjuvant therapy with Jinfeng pills (a traditional Chinese medicine) can increase ovarian blood flow, regulate female endocrine levels, and achieve good therapeutic effect. A systematic review and meta-analysis were conducted to examine the efficacy and safety of Jinfeng pills.
\end{abstract}

Methods: The PubMed (2000 to August 2021), Excerpta Medica Database (2000 to August 2021), Chinese Biomedical Literature (2000 to August 2021), and China National Knowledge Infrastructure (2000 to August 2021) databases were searched. All patients with PCOS were included in the randomized controlled study of Jinfeng pills combined with an adjuvant Western medicine treatment. After screening and a risk of bias assessment, Stata16.0 software was used for the analysis.

Results: A total 7 of articles (comprising 691 patients; 26-83 participants per group) were included in the meta-analysis. The meta-analysis showed that the effective rate the experimental group treated with Jinfeng pills combined with adjuvant Western medicine was higher than that of the control group treated with Western medicine only [relative risk $(\mathrm{RR})=1.15,95 \%$ confidence interval $(\mathrm{CI}): 1.03$ to $1.28 ; \mathrm{P}=0.015$ ]. After treatment, the follicle-stimulating hormone level of the experimental group was significantly lower than that of the control group [mean difference $(\mathrm{MD})=-5.10,95 \% \mathrm{CI}:-7.95$ to $-2.24 ; \mathrm{P}=0.0005$ ], the estradiol level of the experimental group was significantly higher than that of the control group (MD =10.74, 95\% CI: 4.19 to $17.29 ; \mathrm{P}=0.001)$, the testosterone level of the experimental group was significantly lower than that of the control group ( $\mathrm{MD}=-1.17,95 \% \mathrm{CI}:-2.09$ to $-0.25 ; \mathrm{P}=0.01)$, and the pregnancy rate of the experimental group was significantly higher than that of the control group ( $\mathrm{RR}=1.36,95 \% \mathrm{CI}$ : 1.13 to $1.64 ; \mathrm{Z}=3.183$; $\mathrm{P}=0.001)$.

Discussion: The therapeutic effect of Jinfeng pills combined with Western medicine in treating PCOS was better than that of Western medicine alone, and there was no increase in adverse reactions.

Keywords: Jinfeng pill; Chinese medicine; polycystic ovary syndrome (PCOS)

Submitted Nov 17, 2021. Accepted for publication Dec 30, 2021.

doi: 10.21037/apm-21-3638

View this article at: https://dx.doi.org/10.21037/apm-21-3638

(c) Annals of Palliative Medicine. All rights reserved. 


\section{Introduction}

Polycystic ovary syndrome (PCOS), also known as SteinLeventhal syndrome, is a common endocrine disease in women of reproductive age (1). The disease mostly develops in adolescence, and its biochemical blood manifestations are androgen excess, characterized by persistent anovulation, and polycystic changes in the ovaries. Other symptoms include hirsutism, acne, irregular menstruation, infertility, and obesity (2). PCOS also increases the probability of diabetes, hypertension, and endometrial disease lesions (2). At present, the pathogenesis of this disease has not been fully clarified, but some studies have noted that obesity and insulin resistance (IR) increase the incidence of this disease, and hyperandrogenism, which can destroy ovarian function and seriously affect the reproductive health of patients, is closely related to it (3). At present, Western medicine hormone drugs (e.g., ethinylestradiol cyproterone and estradiol dydrogesterone) are the first choice for the treatment of this disease; however, patients can become dependent on such drugs, and PCOS has a high recurrence rate, further, the long-term use of these drugs may lead to liver and kidney dysfunction and increase the risk of endometrial cancer and breast cancer (4). The Jinfeng pill is a traditional Chinese patent medicine, which is the combination of ancient Chinese medicine formula and modern high-tech pharmaceutical technology, containing components such as Festuca arundinacea, motherwort, ginseng, pilose antler, donkey bide gelatin, epimedium, cinnamon and privet seed, and mainly used in the treatment for women with weak kidney function (5). It has been confirmed to increase ovarian blood flow, regulate female endocrine levels, and improve dysmenorrhea, luteal phase dysfunction, and other diseases in female patients (5). As an adjuvant therapy, traditional Chinese medicine can address the shortcomings of Western medicine, and due to its pharmacodynamic properties, traditional Chinese medicine treatments can have positive and lasting long-term effects, and thus has attracted the attention of scholars (6). To date, no systematic analysis has been conducted on the application of this drug in the treatment of PCOS. Thus, we conducted a meta-analysis to examine the efficacy and safety of the Jinfeng pill in the treatment of PCOS to provide a basis for its clinical application.

We present the following article in accordance with the PRISMA reporting checklist (available at https://apm. amegroups.com/article/view/10.21037/apm-21-3638/rc).

\section{Methods}

\section{Criteria for inclusion of literature in the study}

\section{Article type}

The studies included in the meta-analysis were all randomized controlled trials (RCTs); non-randomized concurrent controlled trials were excluded from the metaanalysis.

\section{Participants}

All patients were clinically diagnosed with PCOS (7) based on their androgen (testosterone) levels in serum tests, anovulation or oligoovulation, an ultrasound examination that revealed changes in ovarian morphology, an ovarian volume $>10 \mathrm{~mL}$, or the presence of $>12$ follicles in the ovary. Patients were excluded from the study if they had endocrine disorders caused by medication within 6 months, or had increased androgen secretion caused by congenital diseases.

\section{Description of intervention}

Two groups (an experimental group and control group) were examined in the analysis. The experimental group was treated with Western medicine combined with Jinfeng pills, while the control group was treated with Western medicine only. The treatment and observation time was more than 1 course of treatment (21 days).

\section{Outcome indicators}

The primary outcome indicators were:

(I) Efficacy: treatment efficiency;

(II) Endocrine (hormonal) levels: follicle-stimulating hormone (FSH), luteinizing hormone ( $\mathrm{LH})$, estradiol (E2), testosterone (T) levels;

(III) Ovulation status: ovulation rate and pregnancy rate; and

(IV) Adverse reactions: rate of adverse reactions.

\section{Search strategy and article identification}

The following databases were searched: PubMed (2000 to August 2021), Excerpta Medica Database (2000 to August 2021), Chinese Biomedical Literature (2000 to August 2021), and China National Knowledge Infrastructure (2000 to August 2021). The input keywords for the searches were: (Finfeng pill) AND (Polycystic ovary syndrome/PCOS). 


\section{Article screening and data extraction}

After the article retrieval, Endnote X9 software was used for unified management. After duplicate articles were excluded using the de-weighting function of the software, 2 researchers independently completed the screening of the included studies. Articles that did not meet the abovementioned criteria were excluded based on a reading of the titles and abstracts. After obtaining the original text and data of the remaining articles, they were further screened. If there was a conflict of opinion between the 2 researchers, a 3 rd researcher was consulted to resolve the difference of opinion.

The 2 researchers independently extracted data, including:

(I) Basic information about the article: title, author, contact address, name of publication, and publication time;

(II) Basic characteristics of study: the total number of samples, number of groups, and number of samples in each group;

(III) Basic characteristics of participants: participant age, body mass index (BMI), and disease duration;

(IV) Characteristics of intervention: the different intervention methods used in the experimental group and the control group; and

(V) Results: efficacy, endocrine level, ovarian hemodynamic analysis, and type and number of adverse reactions.

\section{Article bias and evaluation analysis}

The Cochrane Handbook for Systematic Reviews of Interventions was used to assess the risk of bias for the RCTs with a high, low, or unclear indication of risk for each dimension.

\section{Statistical analysis}

Binary variables (i.e., the treatment efficiency rate, ovulation rate, and pregnancy rate) were assessed using the Relative risk (RR) with $95 \%$ confidence interval (CI). The continuous variables (i.e., $F S H, L H, E 2$, and $T$ ) were assessed using the standard mean difference (SMD) with $95 \%$ CI. A P value $<0.05$ was considered statistically significant.

\section{Handling of data loss}

If the article did not provide the data but there was a data address link, the data were obtained from the link. If the data were not provided in the article or were not available via the link, the original author was contacted to obtain the data. If the data could not be obtained, the article was excluded.

\section{Synthetic analysis tools and heterogeneity detection}

Stata 16.0 software was used for the analysis, and forest plots were used to present the analysis results. $\mathrm{I}^{2}$ and $\mathrm{Q}$ tests were used to analyze the heterogeneity of the articles. An $\mathrm{I}^{2}$ value $>50 \%$ or $\mathrm{P}$ value $<0.1$ indicated statistically significant heterogeneity.

\section{Analysis of publication bias}

Funnel plots were used to represent publication bias.

\section{Heterogeneity survey and sensitivity analysis}

The Labbe figure provided by stata 16.0 was used to investigate heterogeneity, and the influence analysis tool of stata 16.0 was used for the sensitivity analysis.

\section{Results}

\section{Literature search results and screening process}

A total of 223 articles were initially retrieved from the database searches. After duplicate articles were removed and the articles were screened, the original data were obtained, and any articles without data were excluded. Ultimately, 7 articles (8-14) were included in the meta-analysis, all of them are Chinese papers. Figure 1 shows the literature search results and screening process.

\section{Basic characteristics of included articles}

Seven articles (comprising 691 patients, 26-83 per group) were included in the meta-analysis. In one study (13), the patients were aged 35-48 years old, and thus were of advanced maternal age. The patients in the other studies were all women of an appropriate age. In all literatures, the treatment methods of Western medicine in the experimental 


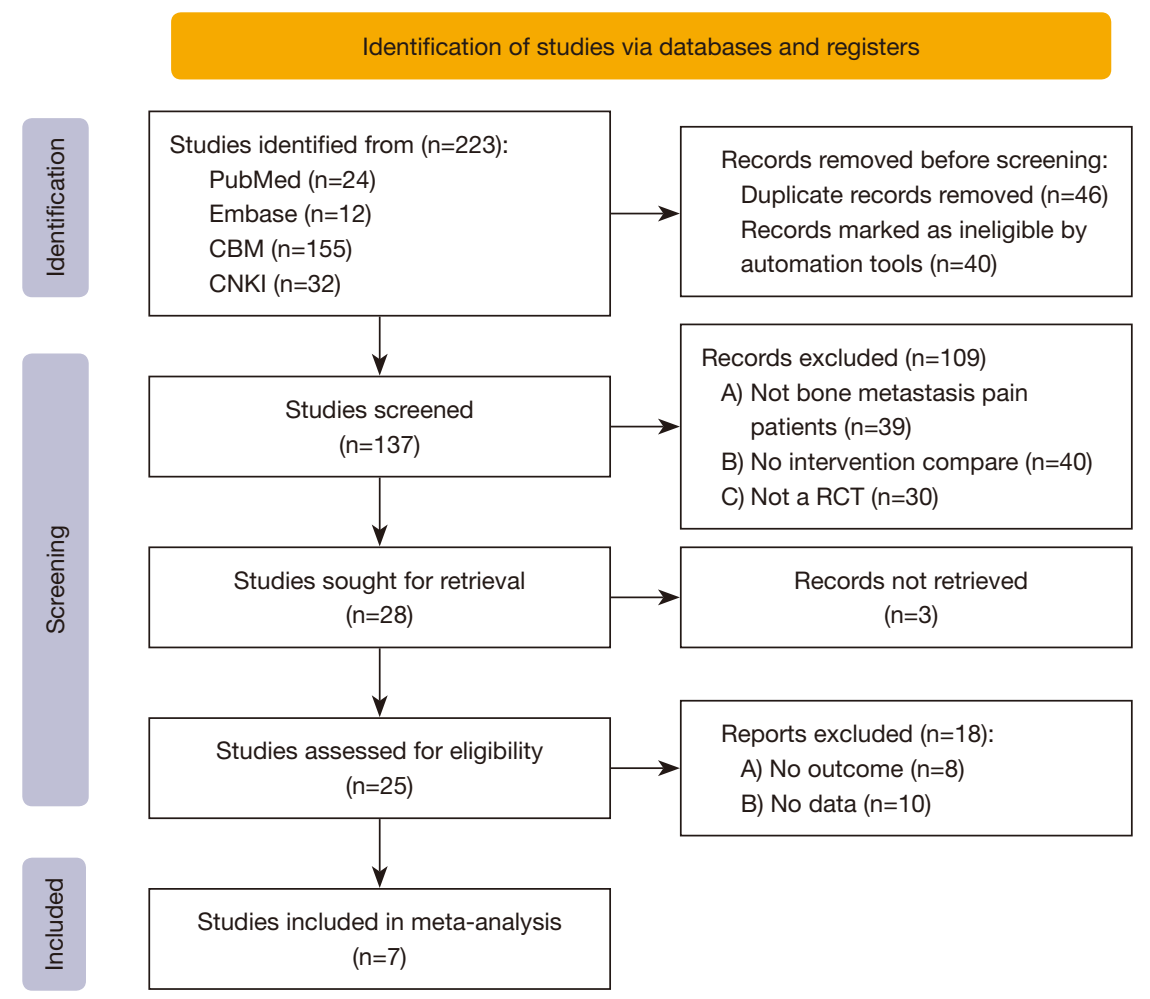

Figure 1 Literature screening flow chart. CBM, Chinese Biology Medical; CNKI, China National Knowledge Infrastructure; RCT, randomized controlled trial.

group were the same as those in the control group. The basic characteristics of the studies are shown in Table 1.

\section{Risk assessment of bias of included articles}

As Table 2 shows, we evaluated the risk of bias based on the Cochrane Handbook for Systematic Reviews of Interventions. All of the articles mentioned using the random grouping method. None of the articles referred to the use of the classification concealment method or blind method. None of the articles described the drop-out cases. Thus, the data may be incomplete. No selective report or other bias was found.

\section{Treatment efficiency rate}

Except for one study (13), all the other studies (comprising 302 patients in the experimental group and 290 patients in the control group) reported on the effective rate of the Jinfeng pills combined with Western medicine in the treatment of PCOS. The meta-analysis showed that the effective rate of the experimental group treated with Jinfeng pills combined with Western medicine was higher than that of the control group treated with Western medicine only [relative risk $(\mathrm{RR})=1.15,95 \% \mathrm{CI}: 1.03$ to $1.28 ; \mathrm{Z}=2.438$, $\mathrm{P}=0.015$; see Figure 2].

\section{Endocrine (sex hormone) levels}

The effect of Jinfeng pills combined with western medicine on the blood level of endocrine of PCOS patients was analyzed (see Table 3). After treatment, the follicle stimulating hormone (FSH) level of the control group was significantly lower than that of the experimental group, the $E 2$ level of the experimental group was significantly higher than that of the control group, and the $T$ level of the experimental group was significantly lower than that of the control group.

\section{Ovulation and pregnancy rates}

A number of articles $(11,12,14)$ reported on the ovulation rate of patients with PCOS after Jinfeng pills combined with an adjuvant Western medicine treatment. The 
Table 1 Basic characteristics table, object characteristics, intervention methods, and outcome indicators of included articles

\begin{tabular}{|c|c|c|c|c|c|c|c|c|}
\hline Author & Year & $\begin{array}{l}\text { Number of } \\
\text { cases }(E / C)\end{array}$ & $\begin{array}{l}\text { Mean age } \\
\text { (years) }\end{array}$ & $\begin{array}{l}\text { Mean } \\
\text { disease } \\
\text { duration } \\
\text { (months) }\end{array}$ & BMI $\left(\mathrm{kg} / \mathrm{m}^{2}\right)$ & Experimental group & Control group & Outcome indicators \\
\hline $\begin{array}{l}\text { Zhou } \\
\text { et al. (8) }\end{array}$ & 2020 & $43 / 43$ & $18-35$ & $1-6$ & $26.53 \pm 3.16$ & $\begin{array}{l}\text { Western medicine } \\
\text { treatment was the same } \\
\text { as the control group. } \\
\text { Add Jinfeng pill, } \\
20 \text { pills/d, divided into } \\
2 \text { doses }\end{array}$ & $\begin{array}{l}\text { Western medicine } \\
\text { treatment: } \\
\text { ethinylestradiol } \\
\text { cyproterone } \\
1 \text { tablet/d; } \\
\text { metformin } \\
\text { hydrochloride } \\
\text { enteric-coated } \\
\text { tablets } 3 \text { times/d }\end{array}$ & $\begin{array}{l}\text { Efficacy rate; ovarian } \\
\text { hemodynamic } \\
\text { parameters: endocrine } \\
\text { level }\end{array}$ \\
\hline $\begin{array}{l}\text { Ding } \\
\text { et al. (9) }\end{array}$ & 2019 & $83 / 83$ & $26.7 \pm 2.8$ & $4.1 \pm 3.3$ & $21.89 \pm 3.39$ & $\begin{array}{l}\text { Western medicine } \\
\text { treatment was the same } \\
\text { as the control group. } \\
\text { Jinfeng pill, } 20 \text { pills/d, } \\
\text { divided into } 2 \text { doses }\end{array}$ & $\begin{array}{l}\text { Ethinylestradiol and } \\
\text { cyproterone } \\
1 \text { tablet/d }\end{array}$ & $\begin{array}{l}\text { Efficacy rate; endocrine } \\
\text { level }\end{array}$ \\
\hline $\begin{array}{l}\text { Gao } \\
\text { et al. (10) }\end{array}$ & 2019 & $38 / 26$ & 20-39 & $4-14$ & $29.78 \pm 10.13$ & $\begin{array}{l}\text { Western medicine } \\
\text { treatment was the same } \\
\text { as the control group. } \\
\text { Jinfeng pills added, } \\
20 \text { pills/d, divided into } \\
2 \text { doses }\end{array}$ & $\begin{array}{l}\text { Estradiol and } \\
\text { dydrogesterone } \\
\text { tablets } 1 \mathrm{mg} / \mathrm{d}\end{array}$ & $\begin{array}{l}\text { Efficacy rate; endocrine } \\
\text { level; ovarian volume }\end{array}$ \\
\hline $\begin{array}{l}\text { Zhuang } \\
\text { et al. (11) }\end{array}$ & 2019 & $60 / 60$ & $23-36$ & - & - & $\begin{array}{l}\text { Western medicine } \\
\text { treatment was the same } \\
\text { as the control group. } \\
\text { Jinfeng pills added, } \\
0.18 \mathrm{~g} / \text { time, twice a day }\end{array}$ & $\begin{array}{l}\text { Clomiphene Citrate } \\
\text { Tablets, } 150 \mathrm{mg} / \mathrm{d}\end{array}$ & $\begin{array}{l}\text { Efficacy rate; ovulation } \\
\text { status; ovulation rate } \\
\text { and pregnancy rate; E2 } \\
\text { level }\end{array}$ \\
\hline $\begin{array}{l}\text { Zhang } \\
\text { et al. (13) }\end{array}$ & 2020 & $60 / 39$ & $35-48$ & - & $\begin{array}{c}19-26 \\
(22.86 \pm 2.37)\end{array}$ & $\begin{array}{l}\text { Western medicine } \\
\text { treatment was the same } \\
\text { as the control group. } \\
\text { Jinfeng pills added, } \\
9 \mathrm{~g} / \mathrm{d}\end{array}$ & $\begin{array}{l}\text { Coenzyme Q10, } \\
10 \mathrm{mg} / \text { time, tid }\end{array}$ & $\begin{array}{l}\text { Endocrine level; ovarian } \\
\text { reserve function; } \\
\text { ovarian artery index; } \\
\text { pregnancy rate }\end{array}$ \\
\hline $\begin{array}{l}\text { Li et al. } \\
(14)\end{array}$ & 2011 & $30 / 30$ & $30.00 \pm 2.49$ & $3.93 \pm 0.37$ & - & $\begin{array}{l}\text { Jinfeng pills, } \\
1.8 \mathrm{~g} / \text { time, bid }\end{array}$ & $\begin{array}{l}\text { Clomiphene } \\
\text { Capsules, } 50 \text { mg/d }\end{array}$ & $\begin{array}{l}\text { Efficacy rate; follicle } \\
\text { diameter; pregnancy } \\
\text { rate }\end{array}$ \\
\hline
\end{tabular}

E, Experimental group; C, Control group; BMI, body mass index. 
Table 2 Risk of bias and quality assessment based on the Cochrane handbook for evaluation of randomized interventions

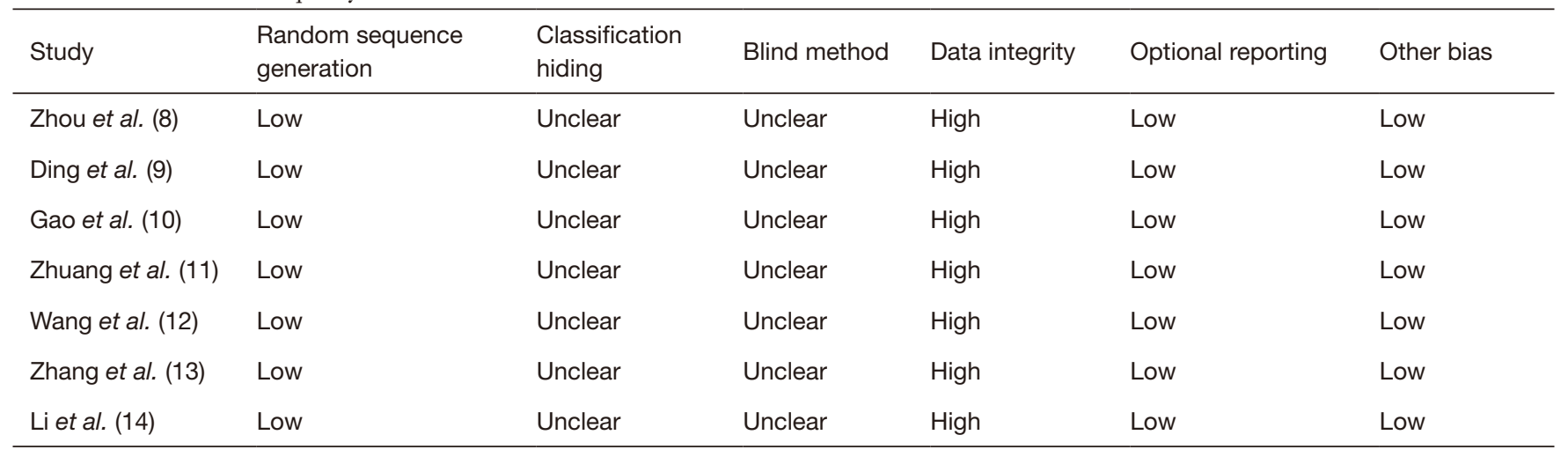

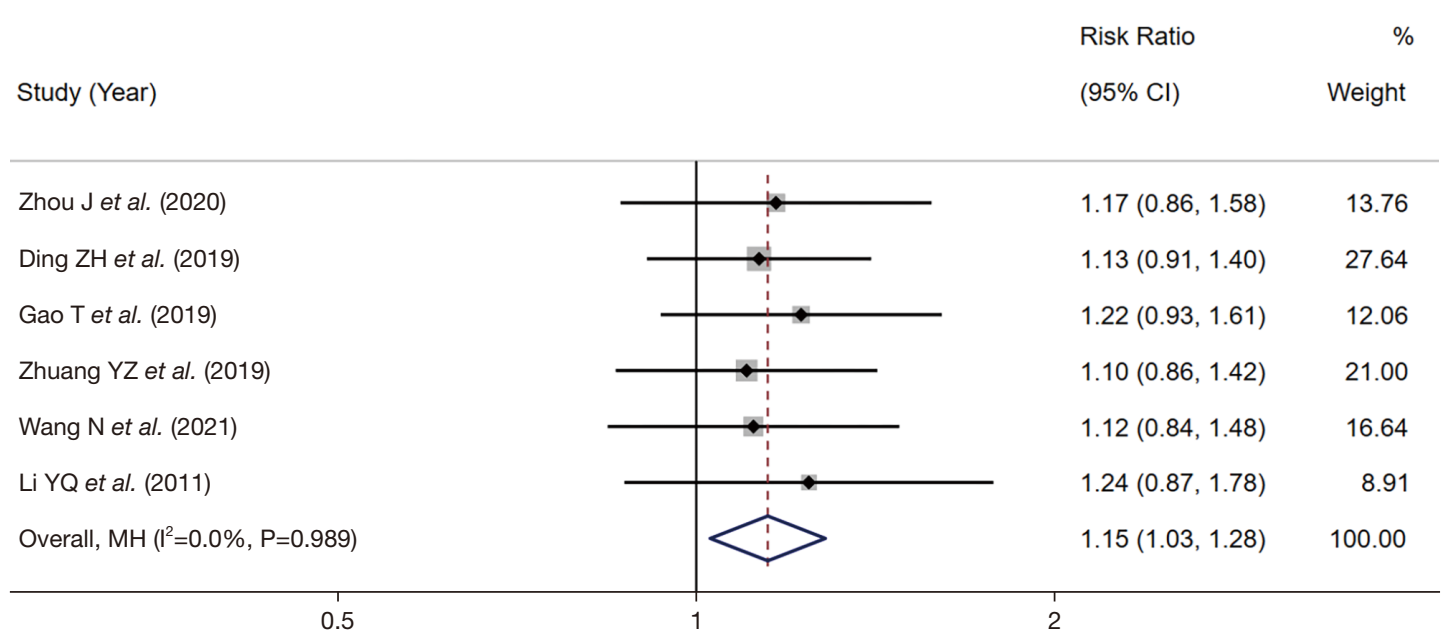

NOTE: Weights are from Mantel-Haenszel model

Figure 2 The effective rates of Jinfeng pills combined with Western medicine in the treatment of PCOS. PCOS, polycystic ovary syndrome.

Table 3 Meta-analysis results of endocrine indicators

\begin{tabular}{|c|c|c|c|c|c|c|}
\hline Factors & $\begin{array}{c}\text { Number of } \\
\text { participating } \\
\text { patients }\end{array}$ & $\begin{array}{l}\text { Number of } \\
\text { articles }\end{array}$ & Statistical method & $I^{2}$ with $P$ value & Effect estimate & $P$ value \\
\hline $\begin{array}{l}\text { Luteinizing } \\
\text { hormone (LH) }\end{array}$ & 415 & $4(8-10,13)$ & MD (IV, Random, 95\% Cl) & $98 \%$ with 0.0001 & $-0.37(-3.71,2.97)$ & 0.83 \\
\hline Testosterone $(\mathrm{T})$ & 412 & $4(8-10,12)$ & MD (IV, Random, 95\% Cl) & $99 \%$ with $<0.00001$ & $-1.17(-2.09,-0.25)$ & 0.01 \\
\hline
\end{tabular}

$\mathrm{MD}$, mean difference; IV, inverse variance; $\mathrm{Cl}$, confidence interval. 


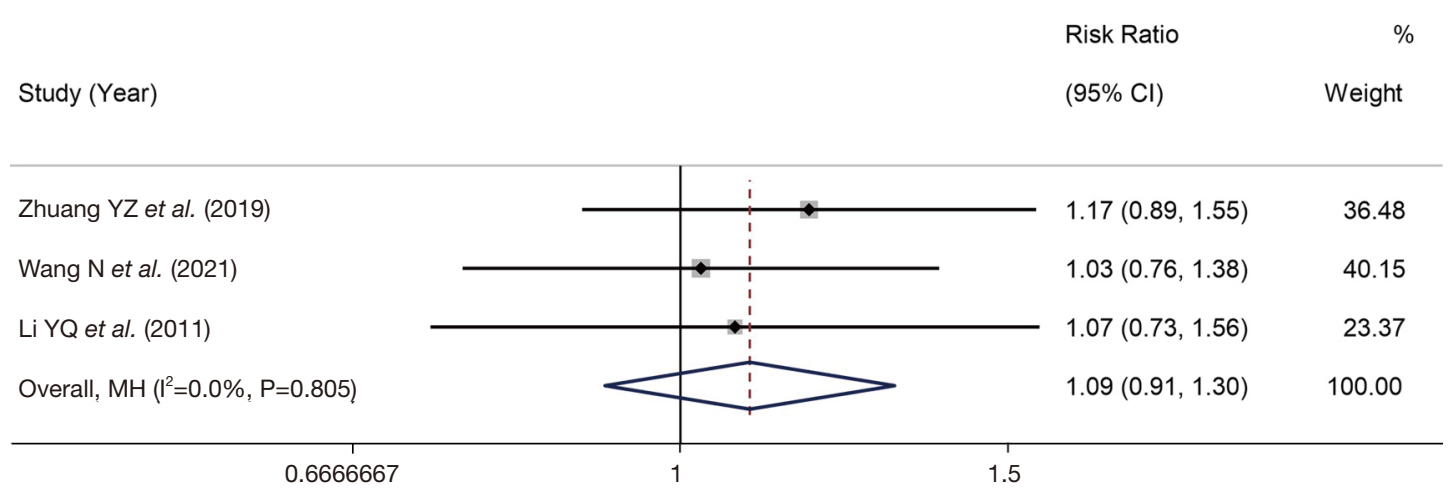

NOTE: Weights are from Mantel-Haenszel model

Figure 3 The ovulation rates of Jinfeng pills combined with Western medicine in the treatment of PCOS. PCOS, polycystic ovary syndrome.

\begin{tabular}{|c|c|c|}
\hline Study (Year) & $\begin{array}{l}\text { Risk Ratio } \\
(95 \% \mathrm{Cl})\end{array}$ & $\begin{array}{r}\% \\
\text { Weight }\end{array}$ \\
\hline Zhuang YZ et al. (2019) & $1.35(1.00,1.83)$ & 38.52 \\
\hline Wang N et al. (2021) & $1.43(1.05,1.94)$ & 33.89 \\
\hline Li YQ et al. (2011) & $1.28(0.87,1.89)$ & 27.59 \\
\hline Overall, $\mathrm{MH}\left(\mathrm{I}^{2}=0.0 \%, \mathrm{P}=0.908\right)$ & $1.36(1.13,1.64)$ & 100.00 \\
\hline
\end{tabular}

NOTE: Weights are from Mantel-Haenszel model

Figure 4 The pregnancy rates of Jinfeng pills combined with Western medicine in the treatment of PCOS. PCOS, polycystic ovary syndrome.

results of the combined analysis showed that there was no significant difference in the ovulation rates between patients after Jinfeng pill adjuvant therapy and Western medicine treatment $(\mathrm{RR}=1.09,95 \% \mathrm{CI}: 0.91$ to $1.30 ; \mathrm{Z}=-2.851$, $\mathrm{P}=0.348$; see Figure 3).

A number of articles $(11,12,14)$ reported on the pregnancy rate of patients with PCOS after Jinfeng pill adjuvant Western medicine treatment. The combined analysis results showed that the pregnancy rate of patients after Jinfeng pills adjuvant therapy was significantly higher than that after Western medicine treatment alone ( $\mathrm{RR}=1.36,95 \% \mathrm{CI}: 1.13$ to $1.64 ; Z=3.183 ; \mathrm{P}=0.001$; see Figure 4).

\section{Adverse reactions}

Two articles $(8,9)$ reported that after adjuvant therapy with
Jinfeng pills, no significant difference in the adverse reactions of patients were observed between the two groups. One study (12) reported 3 cases of night sweats, 1 case of abdominal distension, 4 cases of abdominal pain, 2 cases of nausea, 1 case of itching, and 1 case of headache in the observation group, and the other study reported 4 cases of night sweats, 1 case of abdominal distension, 4 cases of abdominal pain, 3 cases of nausea, 1 case of itching, and 2 cases of headache in the control group. There was no significant difference in the incidence rate of adverse reactions between the two groups $(\mathrm{P}>0.05)$. Thus, Jinfeng pills combined with Western medicine did not increase side effects.

\section{Heterogeneity investigation}

In the analysis of the treatment efficiency rate, the 


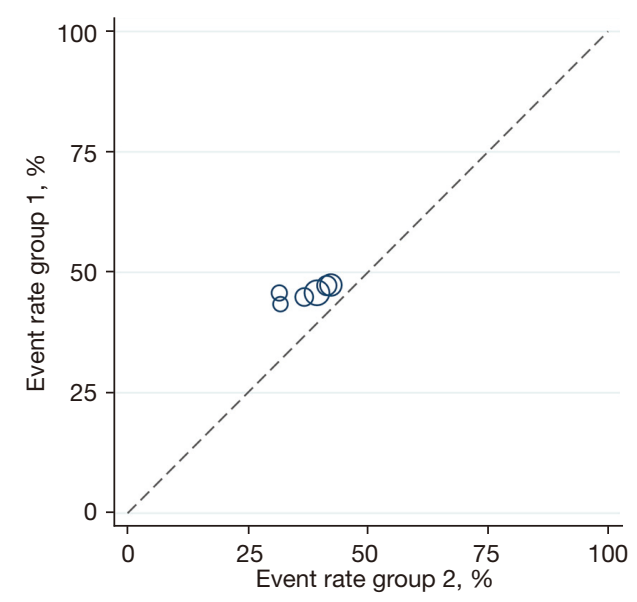

Figure 5 Heterogeneity Labbe diagram of the treatment response rates of Jinfeng pills combined with Western medicine in the treatment of PCOS. PCOS, polycystic ovary syndrome.

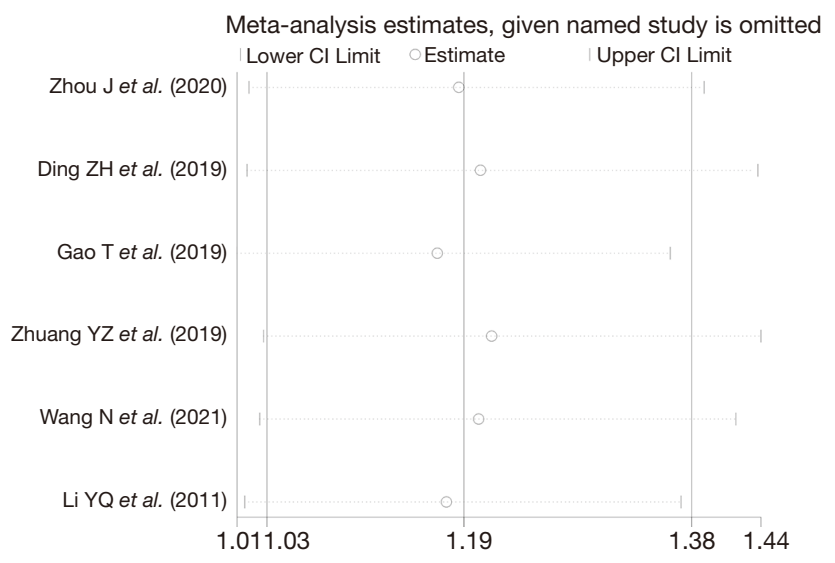

Figure 6 Sensitivity analysis.

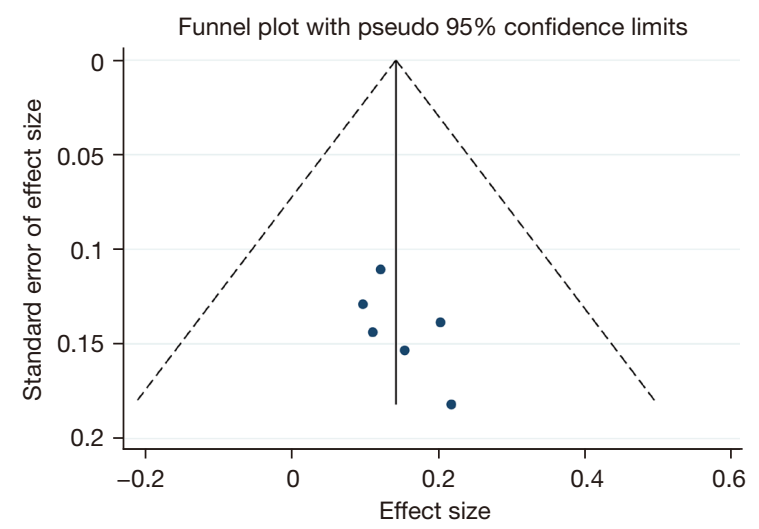

Figure 7 Funnel plot analysis. heterogeneity of 6 articles was $\mathrm{I}^{2}=0 \%(\mathrm{P}=0.989)$, which indicates that there was no significant heterogeneity among the articles. Labbe diagrams are shown in Figure 5.

In the meta-analysis on endocrine (sex hormone) level, there was obvious heterogeneity between the articles. The source of heterogeneity was that the statistical units of $F S H, L H, E 2$, and $T$ indicators were inconsistent across the articles; for example, for the statistics of $\mathrm{FSH}$, one article $(8,9)$ used IU/L as the unit, while another $(10)$ used $\mathrm{mIU} / \mathrm{mL}$ as the unit, and yet another (13) used U/L as the unit.

\section{Sensitivity analyses}

The sensitivity analysis showed that the study results of the 7 articles had a similar distribution on both sides and good stability (see Figure 6).

\section{Publication bias analysis}

The funnel plot showed that the left and right distributions of the 7 articles were basically symmetrical, and thus no significant publication bias was found (see Figure 7).

\section{Discussion}

PCOS is an important cause of infertility in women of reproductive age, and is easily ignored due to the mild symptoms in the early stage of the disease (15). Ovarian enlargement and polycystic albuginea thickening in the PCOS can reduce the pregnancy rate of women, directly lead to infertility in women, and is a predisposing disease of gestational diabetes, cardiovascular disease, endometrial cancer, and type II diabetes (16). The study (17) confirmed that genetics is an important factor in the occurrence of PCOS. Additionally, insulin resistance, hyperandrogenism, and hyperinsulinemia are closely related to the occurrence of syndrome. The increased insulin level in the blood of patients affects the synthesis of hormone proteins in the liver, disorders the secretion of sex hormones, increases the secretion of androgens, and causes PCOS (18). In this study, among the 7 included articles, the Western medicine of ethinylestradiol cyproterone reduced the secretion of pituitary gonadal hormone and reduced the secretion of androgen (19), metformin reduced the insulin level, reduced IR, and increased the sensitivity of tissue insulin (20), and estradiol dydrogesterone and clomiphene citrate improved the ovulation rate, fertilization rate, and pregnancy rate (21). However, these hormonal drugs can delay endometrial development and increase the risk of 
miscarriage. There are more and more reports of treating PCOS by integrating traditional Chinese medicine and Western medicine, and the effect has gradually been widely recognized. In this meta-analysis, a total of 7 articles used Jinfeng pills with Western medicine to treat PCOS, and 6 articles reported on the clinical efficacy of the treatment. The combined effect size showed that Jinfeng pills assisted Western medicine treatments, and had better efficacy than Western medicine alone.

$F S H, L H, E 2$, and $T$ are important indicators for evaluating the level of ovarian function. $\mathrm{FSH}$ and $\mathrm{LH}$ are gonadal hormones secreted by the pituitary gland, which can act on ovarian cortex tissue and regulate ovarian function. The serum E2 level is an important indicator of estrogen, while the serum $\mathrm{T}$ level is an important indicator of androgen. In the pathogenesis of PCOS, the continuous increase of FSH and $\mathrm{LH}$ in patients also leads to ovarian function decline, a serum E2 level decrease, a serum $\mathrm{T}$ level increase, and disordered hormone secretion. After treatment, FSH and LH levels decreased, E2 levels increased, and testosterone T levels decreased. In this study, FSH level was lower, E2 level was higher, and T level was lower in patients treated with Jinfeng pills than those in the control group, but there was no significant difference in LH levels between the two groups, which suggests that Jinfeng pills combined with Western medicine is more beneficial in treating the endocrine disorder of patients and regulating the secretion of hormones than Western medicine alone.

Jinfeng pills contain curculigo, leonurus, ginseng, velvet antler, donkey-hide gelatin, herba epimedii, cinnamomum cassia, ligustrum lucidum. It could improve the deficiency of kidney yang and the biochemical deficiency of Qi and blood which will result in symptoms of dry blood, amenorrhea and sluggish menstrual blood (13). Jinfeng pills all stimulate the ovary and other endocrine glands, promote tubal peristalsis, improve the blood supply of the uterus, improve the body's hypothalamus-pituitary-ovarian axis hormone secretion function, and promote the body's E2 expression (22). The study (23) applied Jinfeng pills to PCOS rat models, and found that ovarian volume decreased, inflammatory factors decreased, and hormone secretion levels tended to be normal in rats treated with Jinfeng pills. A study by Varlı et al. (24) have confirmed that clomiphene, ethinylestradiol, cyproterone and other drugs can solve the problems of superovulation and ovulation, and improve the cleavage rate, biochemical pregnancy rate and fertilization rate during in vitro fertilization, however, these drugs block the role of normal hormones from the receptor level, which can lead to obstruction of endometrial DNA synthesis and retardation of endometrial development, increasing the risk of abortion and reduce the pregnancy rate. The drugs with blood activating effect in Jinfeng pill can also improve the indexes of hemorheology, hemodynamics and microcirculation, regulate the functions of cellular immunity and humoral immunity, and protect the ovary (25).

At the same time, only one article (12) in this study reported on the incidence of adverse reactions in patients treated with Jinfeng pills combined with adjuvant Western medicine, and the results showed that there was no significant difference in the adverse reaction rate of those patients compared to those treated with Western medicine alone. Thus, the adjuvant treatment of Jinfeng pills did not produce additional side effects.

In this study, the heterogeneity survey Labbe diagram and the impact analysis diagram showed that the articles were evenly distributed, indicating that there was no significant heterogeneity between the articles. However, the use of the allocation concealment method and blind method was not mentioned in most articles, and none of the articles described the drop-out cases in detail. The quality of articles may bias the implementation of the results. Additionally, the sample size of the subjects included in the study was small. The efficacy and safety of Jinfeng pills as an adjuvant treatment to Western medicine in the treatment of PCOS still need to be examined in a controlled clinical study with a larger sample size at multi-centers to provide stronger evidence.

\section{Conclusions}

In summary, the therapeutic effect of Jinfeng pills combined with Western medicine in the treatment of PCOS is better than that of Western medicine alone, and Jinfeng pills do not increase the adverse reactions of patients. Due to the small sample size of this study, more RCTs of a higher quality need to be conducted to continue to explore the efficacy of Jinfeng pills as an adjuvant treatment to Western medicine in the treatment of PCOS.

\section{Acknowledgments}

Funding: This work was funded by Hainan Province Clinical Medical Center Project, China.

\section{Footnote}

Reporting Checklist: The authors have completed the 
PRISMA reporting checklist. Available at https://apm. amegroups.com/article/view/10.21037/apm-21-3638/rc

Conflicts of Interest: All authors have completed the ICMJE uniform disclosure form (available at https://apm. amegroups.com/article/view/10.21037/apm-21-3638/coif). The authors have no conflicts of interest to declare.

Ethical Statement: The authors are accountable for all aspects of the work in ensuring that questions related to the accuracy or integrity of any part of the work are appropriately investigated and resolved.

Open Access Statement: This is an Open Access article distributed in accordance with the Creative Commons Attribution-NonCommercial-NoDerivs 4.0 International License (CC BY-NC-ND 4.0), which permits the noncommercial replication and distribution of the article with the strict proviso that no changes or edits are made and the original work is properly cited (including links to both the formal publication through the relevant DOI and the license). See: https://creativecommons.org/licenses/by-nc-nd/4.0/.

\section{References}

1. Goodarzi MO, Dumesic DA, Chazenbalk G, et al. Polycystic ovary syndrome: etiology, pathogenesis and diagnosis. Nat Rev Endocrinol 2011;7:219-31.

2. Lizneva D, Suturina L, Walker W, et al. Criteria, prevalence, and phenotypes of polycystic ovary syndrome. Fertil Steril 2016;106:6-15.

3. Diamanti-Kandarakis E, Dunaif A. Insulin resistance and the polycystic ovary syndrome revisited: an update on mechanisms and implications. Endocr Rev 2012;33:981-1030.

4. Ruan X, Kubba A, Aguilar A, et al. Use of cyproterone acetate/ethinylestradiol in polycystic ovary syndrome: rationale and practical aspects. Eur J Contracept Reprod Health Care 2017;22:183-90.

5. Liu S, Xie KH, Wei RX, et al. Jinfeng pill combined with recombinant human growth hormone improves endometrial receptivity in patients with thin endometrial infertility. International Journal of Reproductive Health 2021;40:93-7.

6. Zhou J. Observation on the effect of Jinfeng pill combined with estradiol valerate tablets in the treatment of thin endometrial infertility. Journal of Clinical Rational Drug Use 2020;13:20-1.

7. Williams T, Mortada R, Porter S. Diagnosis and
Treatment of Polycystic Ovary Syndrome. Am Fam Physician 2016;94:106-13.

8. Zhou J, Zhou Z, Ma N. Effects of Jinfeng pill combined with western medicine on ovarian hemodynamics and endocrine indexes in patients with PCOS. World Journal of Traditional Integrated Chinese and Western Medicine 2020;15:2252-5.

9. Ding ZH, Ding YM, Ding ZG, et al. Efficacy of metformin sustained release tablets combined with Jinfeng pill in the treatment of polycystic ovary syndrome. Chinese Practical Medicine 2019;14:114-6.

10. Gao T. Effect of Jinfeng Pill on sex hormone and ovarian volume in patients with POI. Modern Practical Medicine 2019;31:197-9.

11. Zhuang Y, Yao M, Jiang R. Clinical study on Jinfeng pill combined with clomiphene citrate tablets in the treatment of ovulation disorder in polycystic ovary syndrome. Jiangxi Medicine 2019;54:946-8.

12. Wang N, Shao HF, Xing CY, et al. Effect of Jinfeng pill combined with Clomiphene on androgen level in patients with PCOS complicated with infertility. Laboratory Medicine and Clinic 2021;18:1246-9, 1253.

13. Zhang YJ, Li H, Lu J. Effects of coenzyme Q10 combined with Jinfeng Pill on ovarian function and IVF-ET outcome in elderly pregnant women. Chinese Journal of Medical Frontier (Electronic Edition), 2020;12:92-6.

14. Li YQ, Xu DS, Huo HJ. Clinical study on Jinfeng pill in the treatment of anovulatory infertility. Chinese Journal of Experimental Prescriptions 2011;17:242-3.

15. Bednarska S, Siejka A. The pathogenesis and treatment of polycystic ovary syndrome: What's new? Adv Clin Exp Med 2017;26:359-67.

16. Jin P, Xie Y. Treatment strategies for women with polycystic ovary syndrome. Gynecol Endocrinol 2018;34:272-7.

17. Khan MJ, Ullah A, Basit S. Genetic Basis of Polycystic Ovary Syndrome (PCOS): Current Perspectives. Appl Clin Genet 2019;12:249-60.

18. Moghetti P. Insulin Resistance and Polycystic Ovary Syndrome. Curr Pharm Des 2016;22:5526-34.

19. Liu $Z$, Song $Y, X u Y$, et al. The comparison of the effectiveness and safety of drospirone ethinyl estradiol and ethinyl estradiol cyproterone in the treatment of polycystic ovarian syndrome: A protocol for systematic review and meta-analysis. Medicine (Baltimore) 2020;99:e23811.

20. Fruzzetti F, Perini D, Russo M, et al. Comparison of two insulin sensitizers, metformin and myo-inositol, in women with polycystic ovary syndrome (PCOS). Gynecol 
Endocrinol 2017;33:39-42.

21. Legro RS, Brzyski RG, Diamond MP, et al. Letrozole versus clomiphene for infertility in the polycystic ovary syndrome. N Engl J Med 2014;371:119-29. Erratum in: N Engl J Med 2014;317:1465.

22. Gao RM, Yang ZQ, Jiang JJ. Clinical observation on Jinfeng pill promoting endometrial repair after abortion in 30 cases. China Maternal and Child Health Research 2016;27:257-8.

23. Long H, Ni XR, Hu GH, et al. Preliminary study on the preventive and therapeutic effect and mechanism of Tonifying the kidney and activating blood circulation on rats with polycystic ovary syndrome. World Journal of

Cite this article as: $\mathrm{Xu} \mathrm{Y,} \mathrm{Han} \mathrm{YM,} \mathrm{Xu} \mathrm{W,} \mathrm{Shi} \mathrm{C,} \mathrm{Chen} \mathrm{YE,}$ Li N. Clinical efficacy and safety of the Jinfeng pill in the adjuvant treatment of infertility in patients with polycystic ovary syndrome: a systematic review and meta-analysis of randomized controlled trial. Ann Palliat Med 2022;11(1):352362. doi: $10.21037 / \mathrm{apm}-21-3638$
Traditional Integrated Chinese and Western Medicine 2019;14:1105-10.

24. Varlı B, Şükür YE, Özmen B, et al. Anorexigenic peptide (leptin, obestatin, nesfatin-1) levels and their impact on assisted reproductive technology treatment outcomes in patients with polycystic ovary syndrome. Clin Exp Reprod Med 2021;48:368-73.

25. Zhang R, Sun J. Clinical effect of Jinfeng pill combined with bujiale on thin endometrial infertility. World Journal of Integrated Traditional Chinese and Western Medicine 2019;14:1263-6.

(English Language Editor: L. Huleatt) 